\title{
Influência da granulometria e do pH no processo de dessorção de amônia em torres de recheio
}

\author{
Influence of particle size and $\mathrm{pH}$ on desorption of \\ ammonia process in towers filling
}

Data de entrada: $31 / 01 / 2014$

Data de aprovação: 05/06/2014

Isabelle da Cunha Dutra / Valderi Duarte Leite

DOI: $10.4322 /$ dae.2014.138

\section{Resumo:}

A dessorção de amônia apresenta-se como alternativa para remoção do nitrogênio amoniacal do lixiviado de aterro sanitário, por meio da transferência de massa da fase líquida para gasosa. Para não contribuir com a poluição atmosférica, o gás amônia liberado durante o processo foi submerso em solução ácida. A neutralização da amônia gera aquamônia, produto que pode ser utilizado como fertilizante na agricultura. $O$ trabalho foi realizado na EXTRABES, na cidade de Campina Grande, estado da Paraíba, utilizando um sistema experimental constituído por três torres de recheio e um reator para recepção do gás amônia. $O$ lixiviado utilizado durante o processo foi coletado no aterro sanitário da cidade de João Pessoa (PB). O sistema experimental foi monitorado com pH do lixiviado variando de 9 a 11 e sob três granulometrias de recheio para as torres (brita $\mathrm{n}^{\circ} 12,19$ e 25). A eficiência de remoção de nitrogênio amoniacal variou em função do $\mathrm{pH}$ e da granulometria do recheio aplicado às torres.

Palavras-chave: Lixiviado. Dessorção de amônia. Torres de recheio.

\section{Abstract:}

The desorption of ammonia is presented as an alternative for removal of ammoniacal nitrogen from landfill leachate by means of mass transfer from gas to liquid phase. To not contribute to air pollution, the ammonia gas released during the process was submerged in acid solution. The neutralization of ammonia aqua ammonia generates product which can be used as fertilizer in agriculture. The study was conducted at EXTRABES in Campina Grande Paraiba state, using the experimental system consists of three towers and filling a reactor for receiving the ammonia gas. The leachate used in the process were collected in the landfill of the city of João Pessoa (PB). The experimental system was monitored with $\mathrm{pH}$ of the leachate ranging 9-11 and under three grainy filling for the towers (gravel No. 12, 19 and 25). The removal efficiency of ammonia nitrogen varied as a function of $p H$ and particle size of the filling applied towers.

Keywords: Leachate. Desorption of ammonia. Towers filling.

Isabelle da Cunha Dutra

Mestre em Ciência e graduada em Química Industrial pela Universidade Estadual da Paraíba (UEPB).

Valderi Duarte Leite

Doutor em Hidráulica e Saneamento pela Escola de Engenharia de São Carlos da Universidade de São Paulo. Mestre em Engenharia Sanitária pela Universidade Federal da Paraíba. Professor do Departamento de Engenharia Sanitária Ambiental da UEPB.

Endereço para correspondência:

Avenida Floriano Peixoto, 5255 - Serrotão - Campina Grande - PB

CEP: $58434-500$

Tel: (83) 9660-8098

E-mail: Isabelle_pbahotmail.com 


\section{INTRODUÇÃO}

No Brasil, são gerados cerca de 62.730.096 t/ano de Resíduos Sólidos Urbanos (RSUs), dos quais $90,17 \%$ são coletados, sendo que $58 \%$ têm como destinação aterros sanitários e os $42 \%$ restantes correspondem a 76 mil toneladas diárias, que são encaminhadas para lixões ou aterros controlados (ABRELPE, 2012).

Um dos grandes problemas encontrados no gerenciamento de aterros sanitários de resíduos urbanos diz respeito à produção e ao tratamento de alguns subprodutos. Entre os subprodutos resultantes do processo de bioestabilização da matéria orgânica putrescível, o lixiviado necessita de uma atenção especial, principalmente nos casos em que o aterro sanitário está situado em áreas com alta precipitação pluviométrica, onde a produção desse líquido é abundante e, consequentemente, o risco de contaminação do solo, de lençóis freáticos e de leitos de rios é alto, podendo ocasionar forte impacto ambiental.

O lixiviado é composto por elevados teores de material carbonáceo e nitrogenado. 0 material carbonáceo geralmente é de difícil biodegradação, o que compromete o desempenho do processo de tratamento. Sendo assim, é necessária a realização do tratamento físico e químico, seguido do tratamento biológico, visando à redução da concentração de nitrogênio amoniacal e formação de melhores condições para realização do tratamento biológico (KIM et al. 2007).

Uma alternativa que vem sendo estudada e tem se mostrado eficiente na remoção de nitrogênio amoniacal em lixiviado é a dessorção de amônia. Esse processo baseia-se na transferência de massa da fase líquida para a fase gasosa, mediante a injeção de ar no líquido por meio de difusores ou outros mecanismos de aeração, após ser estabelecida a condição de Potencial Hidrogeniônico (pH) adequada (GOMIDE, 1983).

\section{LIXIVIADO}

Os resíduos sólidos, após a deposição em aterros sanitários, sofrem alterações físicas, químicas e biológicas. Consequentemente, a degradação da fração orgânica, em combinação com a percolação de águas pluviais, leva à geração de um líquido altamente contaminante, chamado lixiviado (KURNIAWAN, et al., 2006).

A composição dos lixiviados de aterro sanitário é variável, dependendo do tipo e estágio de decomposição do RSU, grau de estabilidade dos resíduos sólidos, hidrologia local, variação climática sazonal, umidade e idade do aterro. De acordo com Abbas et al. (2009), a quantidade de lixiviado gerado em um aterro sanitário depende da percolação de águas pluviais por meio dos resíduos, processos bioquímicos das células dos resíduos, teor de água inerente e grau de compactação dos resíduos no aterro. Entre as fontes que contribuem para sua formação, a água da chuva, que percola pela camada de cobertura é, sem dúvida, a mais relevante.

Os parâmetros físicos, químicos e biológicos mais frequentes utilizados para determinar a composição do lixiviado são pH, , Demanda Química de Oxigênio (DQO), Demanda Bioquímica de Oxigênio $\left(\mathrm{DBO}_{5}\right)$, Carbono Orgânico Total (COT), Nitrogênio Total Kjeldahl (NTK), nitrogênio amoniacal, alcalinidade, série de sólidos, ácidos orgânicos voláteis, metais pesados e toxicidade. Tais parâmetros são essenciais para controlar a descarga do lixiviado tratado nos corpos aquáticos receptores.

A composição e característica dos lixiviados de aterro sanitário são variáveis. Segundo Atmaca (2009), dependem de fatores como: tipo de resíduo aterrado, grau de decomposição, clima, estação do ano, idade do aterro, profundidade do resíduo aterrado e tipo de operação de aterro.

A remoção de material carbonáceo e nitrogenado, baseada na DQQO, na DBO e na remoção de amônia, é uma das condições habituais antes da descarga do lixiviado em corpos hídricos (ATMACA, 2009). 
Os métodos de tratamento biológico são eficazes para a redução da matéria orgânica em lixiviados de aterros sanitários recentes, porém apresentam ineficácia para lixiviado de aterro sanitário velho. Os lixiviados de baixa razão de biodegradabilidade exigem técnicas de tratamento físico e químico para remover a matéria orgânica (SINGH et al. 2012).

\section{A QUÍMICA DO NITROGÊNIO}

A química do nitrogênio é complexa devido aos diversos estados de oxidação que o elemento pode assumir na natureza. Além disso, esses estados de oxidação podem ser modificados positiva ou negativamente por microrganismos, dependendo das condições ambientais que prevalecem, sejam elas aeróbias, anaeróbias ou anóxicas. As formas mais comuns de nitrogênio em águas residuárias são: amônia $\left(\mathrm{NH}_{3}\right)$, íon amônio $\left(\mathrm{NH}_{4}^{+}\right)$, gás nitrogênio $\left(\mathrm{N}_{2}\right)$, íon nitrito $\left(\mathrm{NO}_{2}{ }^{-}\right)$e íon nitrato $\left(\mathrm{NO}_{3}{ }^{-}\right)$ (SAWYER et al., 2003).

Nos recursos hídricos, a amônia em sua forma não ionizada $\left(\mathrm{NH}_{3}\right)$ pode ser tóxica para diversos organismos, afetando a taxa de crescimento ou, ainda, comprometendo a qualidade desses recursos hídricos devido à eutrofização, causada pelo excesso de amônia, além do fósforo. Por isso, o lixiviado produzido e coletado nos aterros sanitários necessita de tratamento antes do seu lançamento no meio ambiente. Segundo a Resolução $n^{\circ}$ 430/2011 do Conselho Nacional do Meio Ambiente (CONAMA), a máxima concentração de lançamento em corpos aquáticos permitida para o nitrogênio amoniacal é de 20 mg/L.

Em meio aquoso e pH acima de 7, a amônia encontra-se em equilíbrio sob duas formas, que são a iônica $\left(\mathrm{NH}_{4}^{+}\right)$e a molecular gasosa $\left(\mathrm{NH}_{3}\right)$. A equação de equilíbrio pode ser descrita da seguinte forma:

$\mathrm{NH}_{3(\mathrm{~g})}+\mathrm{H}_{2} \mathrm{O}_{(\mathrm{l})} \leftrightarrow \mathrm{NH}_{4}^{+}{ }_{(\mathrm{aq})}^{+}+\mathrm{OH}^{-}{ }_{(\mathrm{aq})}$
O equilíbrio dessa equação depende de alguns fatores, destacando-se como principais duas variáveis: $\mathrm{pH}$ e temperatura. Portanto, quanto mais elevado for o $\mathrm{pH}$, maior será o percentual de amônia na água residuária, uma vez que a Equação 1 se desloca para a esquerda e o íon amônio $\left(\mathrm{NH}_{4}^{+}\right)$ se converte em gás amônia $\left(\mathrm{NH}_{3}\right)$.

Com base na Equação 1 e admitindo que o valor da constante de dissociação $\left(\mathrm{K}_{\mathrm{b}}\right)$ a $25^{\circ} \mathrm{C}$ é igual a 1,8 $10^{-5}$, a constante de dissociação pode ser descrita pela Equação 2.

$\mathrm{K}_{\mathrm{b}}=\frac{\left[\mathrm{NH}_{4}^{+}\right] \times[\mathrm{OH}-]}{\left[\mathrm{NH}_{3}^{+}\right]}$

Em que:

$\mathrm{K}_{\mathrm{b}}$ : constante de dissociação de basicidade; $\mathrm{NH}_{4}^{+}$: concentração do íon amônio (mol.L-1 $)$; $\mathrm{OH}^{-}$: concentração do íon hidroxila (mol. $\left.\mathrm{L}^{-1}\right)$; $\mathrm{NH}_{3}$ : concentração do gás amônia $\left(\mathrm{mol} . \mathrm{L}^{-1}\right)$.

Utilizando as constantes de dissociação da água e da base, a Equação 2 passará a ser representada pelas Equações 3 e 4.

$\alpha_{\mathrm{NH}_{4}^{+}}=\frac{k_{b} \times \mathrm{H}^{+}}{k_{b} \times \mathrm{H}^{+}+k_{w}}$

$\alpha_{\mathrm{NH}_{3}}=\frac{k_{w}}{k_{b} \times H^{+}+k_{w}}$

Em que:

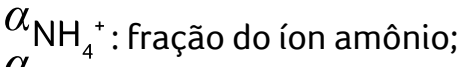

$\alpha_{\mathrm{NH}_{4} \text { : fração do gás amônia; }}$

$\mathrm{k}_{\mathrm{b}}$ : constante de dissociação da base;

$\mathrm{H}^{+}$: concentração do íon hidrogênio $\left(\mathrm{mol}^{-\mathrm{L}^{-1}}\right.$ );

$\mathrm{k}_{\mathrm{w}}$ : constante de dissociação da água. 
Com base nas Equações 3 e 4, é possível obter o diagrama que apresenta o comportamento da distribuição das espécies de íon amônio e gás amônia em função do pH (Figura 1).

Elevando o $\mathrm{pH}$ do meio aquoso, o equilíbrio da reação se desloca para a esquerda, favorecendo a maior presença de amônia. No pH em torno de 7 , praticamente todo o nitrogênio amoniacal encontra-se na forma de $\mathrm{NH}_{4}{ }^{+}$, enquanto, no $\mathrm{pH}$ em tor-

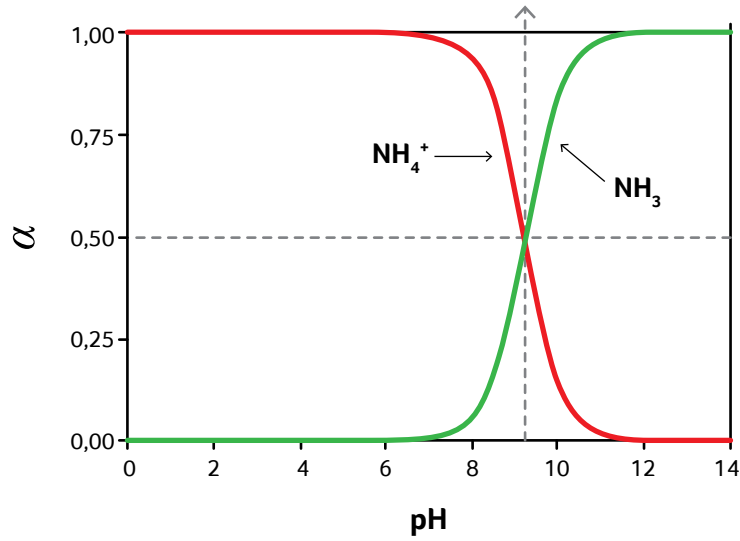

Figura 1 - Distribuição das espécies de íon amônio e gás amônia em função do pH.

Fonte: Campos et al. (2010).

no de 9,2 , cerca de $50 \%$ do nitrogênio amoniacal está na forma de $\mathrm{NH}_{3}$ e $50 \%$, na forma de $\mathrm{NH}_{4}{ }^{+}$. Em $\mathrm{pH}$ superior a 11, praticamente todo o nitrogênio amoniacal está na forma de gás. Sendo assim, é possível retirar o gás amônia do meio aquoso, que ele pode ser removido por volatilização, ao passo que o íon amônio não pode.

\section{DESSORÇÃO DE AMÔNIA}

A dessorção consiste em um processo físico que se baseia na transferência de massa de um composto indesejável volátil da fase líquida para a fase gasosa, por meio da injeção de ar que passa pelo meio líquido, mediante mecanismos de aeração. A transferência de massa da fase líquida para a fase gasosa recebe o nome técnico de dessorção, embora o termo mais utilizado na engenha- ria sanitária e ambiental seja stripping (METCALF; EDDY, 2003).

A introdução mecânica de ar no meio líquido pela ação da circulação dessa massa de ar favorece a expulsão ou o arraste do gás amônia, normalmente para a atmosfera. Por isso, a principal desvantagem desse processo é o impacto ambiental, devido à liberação de gás amônia na atmosfera. Portanto, há necessidade de tratamento posterior do gás, geralmente utilizando ácido clorídrico ( $\mathrm{HCl})$ ou ácido sulfúrico $\left(\mathrm{H}_{2} \mathrm{SO}_{4}\right)$, para absorção da amônia (DI IACONI et al., 2010; RENOU et al., 2008).

A dissolução do gás amônia em líquidos depende da pressão parcial do gás na atmosfera adjacente. Se essa pressão parcial for reduzida, a amônia tenderá a sair da água. Então, é possível remover amônia colocando gotas do efluente em questão em contato com ar livre de amônia. Nessas condições, a amônia sairá da fase líquida, numa tentativa de restabelecer o equilíbrio. Caso o gás de arraste escoe continuamente, em tese chegará um momento em que todo o composto indesejado será removido da fase líquida (SOUTO, 2009).

Portanto, a presente pesquisa objetiva avaliar os efeitos causados pela granulometria do material de recheio e $\mathrm{pH}$ do lixiviado no processo de dessorção de amônia de lixiviado de aterro sanitário em torres de recheio.

\section{MATERIAL E MÉTODOS}

O sistema experimental foi construído, instalado e monitorado nas dependências físicas da Estação Experimental de Tratamento Biológico de Esgoto Sanitário (EXTRABES), instituição da UEPB, situada geograficamente no bairro Tambor, na cidade de Campina Grande, estado da Paraíba, Nordeste do Brasil.

O lixiviado utilizado foi coletado no aterro sanitário metropolitano da cidade de João Pessoa (PB), localizado no Engenho Mussuré no Distrito Industrial, a 5 km da BR-101, onde se recebe o resíduo 


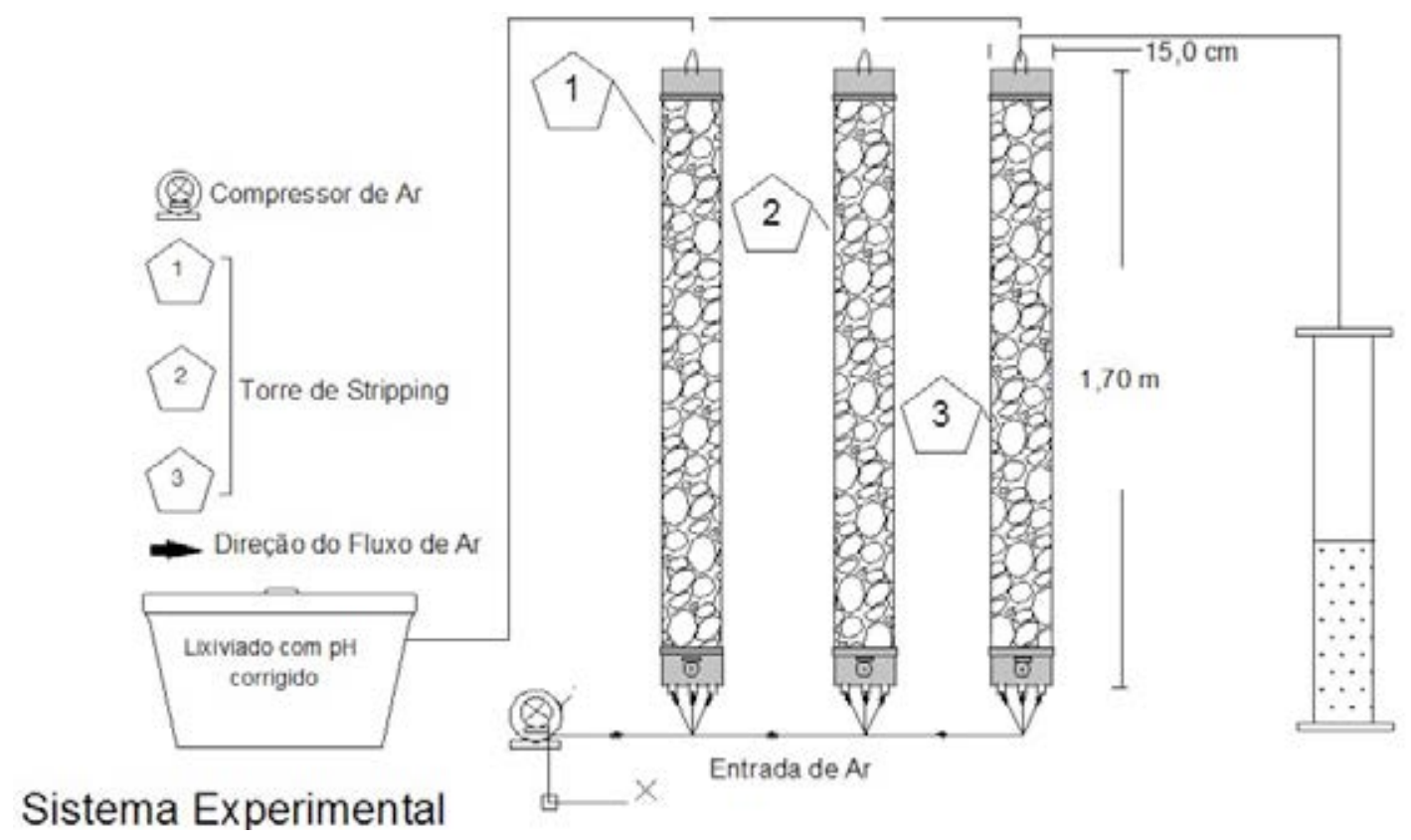

Figura 2 - Desenho do sistema experimental.

do Consórcio de Desenvolvimento Intermunicipal da Região Metropolitana, constituído pelas cidades de Santa Rita, Bayeux, Cabedelo, Lucena, Conde, Cruz do Espírito Santo e João Pessoa.

Esse lixiviado foi coletado e transportado até as dependências da EXTRABES por meio de carros -tanque, onde foi realizada a caracterização física e química, e em seguida armazenado para posteriormente ser utilizado nas torres de recheio.

O sistema experimental foi dimensionado em escala piloto, sendo constituído por um reservatório de polietileno para armazenamento do lixiviado in natura; três torres de recheio, construídas de PVC com 150 mm de diâmetro e 1,2 m de altura, tendo capacidade volumétrica unitária de 20 litros; um compressor de ar e um reator para recepção do gás amônia liberado durante o processo de dessorção. Na Figura 2, apresenta-se o esquema de funcionamento das torres de recheio e recolhimento de amônia.

Os experimentos foram realizados em regime de batelada. Em todas elas, foram introduzidos $5 \mathrm{~L}$ de lixiviado em cada torre de recheio. Em sentido contrário ao deslocamento do líquido, o ar era injetado na parte inferior das torres, por meio de um compressor. À medida que o ar entrava em contato com o líquido, o gás amônia era arrastado para fora das torres com o ar, por meio da saída superior. $O$ efluente gasoso era conduzido para o reator de recolhimento contendo solução de ácido bórico $2 \mathrm{~N}$.

Os experimentos realizaram-se em nove fases distintas, nas quais foram relacionados três níveis de espaços vazios (determinados pelas granulometrias dos materiais de recheio) com três tipos de correção para o pH do lixiviado, a fim de avaliar a influência desses itens na dessorção de amônia.

\section{MATERIAL DE RECHEIO}

De acordo com Foust et al. (1982), a escolha do material de recheio utilizado nas torres depende de fatores como: ser quimicamente inerte; ser resistente; proporcionar uma passagem adequada do fluido sem implicar grande perda de carga; 
oferecer um contato sódio-fluido efetivo (molhabilidade); e apresentar baixo custo.

Optou-se por utilizar brita no recheio das torres de dessorção, uma vez que apresenta todas as características necessárias, além de ser um material de fácil acesso. Foram escolhidos três granulometrias diferentes de brita para o presente estudo (grande, intermediária e pequena).

A brita utilizada como material de recheio nas torres foi caracterizada de acordo com a norma da Associação Brasileira de Normas Técnicas (ABNT) NBR 7211, por meio do método de peneiramento, apresentando granulometrias de $\mathrm{n}^{\circ} 12,19 \mathrm{e}$ 25 , possuindo espaço vazio de $49,9 \%, 48,5 \%$ e $47 \%$, respectivamente.

Cada ensaio foi realizado utilizando uma única granulometria de brita como recheio e o lixiviado com único $\mathrm{pH}$ porvez nas três torres. Estas funcionavam simultaneamente em sistema de triplicata. Para determinar o número de tratamentos a ser realizados, foi feito um planejamento experimental do tipo fatorial completo. Pelo fato de serem estudados três níveis de espaço vazio nas torres e três níveis de $\mathrm{pH}$, nove diferentes condições de tratamento foram geradas, conforme dados mostrados na Tabela 1.

Tabela 1 - Parâmetros operacionais aplicados às torres de recheio.

\begin{tabular}{|c|c|c|}
\hline $\begin{array}{c}\text { Parâmetro/ } \\
\text { tratamento }\end{array}$ & pH & $\Phi(\%)$ \\
\hline pH9B1 & 9 & 49,9 \\
\hline pH10B1 & 10 & 49,9 \\
\hline pH11B1 & 11 & 49,9 \\
\hline pH9B2 & 9 & 48,5 \\
\hline pH10B2 & 10 & 48,5 \\
\hline pH11B2 & 11 & 48,5 \\
\hline pH9B3 & 9 & 47,0 \\
\hline pH10B3 & 10 & 47,0 \\
\hline pH11B3 & 11 & 47,0 \\
\hline
\end{tabular}

Nota: $\Phi(\%)=$ porcentagem de espaço vazio.

\section{MONITORAMENTO DO SISTEMA EXPERIMENTAL}

O monitoramento do sistema experimental consistiu na alimentação ascendente de ar e descendente de lixiviado. As amostras de efluente líquido foram coletadas com frequência de 20 minutos para determinação dos parâmetros analíticos monitorados, de acordo com os métodos preconizados pela American Public Health Association (APHA, 2005).

$\mathrm{O}$ processo iniciou-se com a correção do $\mathrm{pH}$ do lixiviado, por meio de hidróxido de cálcio. Em seguida, as três torres, contendo brita com a mesma granulometria, receberam o lixiviado em temperatura ambiente. 0 gás amônia, com o ar que saía das torres, foi conduzido até um reator de recolhimento para não ser lançado na atmosfera.

O reator de recolhimento de amônia foi formado por um recipiente de vidro com forma cilíndrica, contendo ácido bórico $2 \mathrm{~N}$, e fechado com tampa; a cada ensaio, foi totalmente vedado com cola de silicone, a fim de evitar perda de gás. Ao entrar em contato com a solução ácida, o gás amônia foi neutralizado formando aquamônia, substância que pode ser utilizada como fertilizante na agricultura.

\section{RESULTADOS E DISCUSSÕES}

$\mathrm{Na}$ Tabela 2, são apresentados os dados advindos da caracterização química do lixiviado utilizado para realização dos ensaios do processo de dessorção de amônia.

A principal forma de nitrogênio encontrada no lixiviado do aterro sanitário da região metropolitana da cidade de João Pessoa (PB) foi o nitrogênio amoniacal, correspondendo a $91 \%$. Essa grande concentração de $\mathrm{N}-\mathrm{NH}_{4}{ }^{+}$indica dificuldade para aplicação de tratamentos biológicos, requerendo a utilização de um processo físico, como, por exemplo, a dessorção de amônia, para redução dessa concentração a um patamar que possa viabilizar um posterior tratamento biológico. 
Tabela 2 - Dados da caracterização química e física do lixiviado in natura do aterro sanitário da região metropolitana da cidade de João Pessoa (PB).

\begin{tabular}{|c|c|c|c|c|}
\hline Parâmetro & Unidade & Valores médio & Valor mínino & Valor máximo \\
\hline $\mathrm{pH}$ & - & 7,8 & 7,6 & 8,0 \\
\hline Alcalinidade total & $\mathrm{mg} \cdot \mathrm{CaCO}_{3} \cdot \mathrm{L}^{1}$ & 16.974 & 13.127 & 19.821 \\
\hline Ácidos graxos voláteis & $\mathrm{mg} \mathrm{H}-\mathrm{Ac} \cdot \mathrm{L}^{-1}$ & $3.388,5$ & 2.420 & 4.357 \\
\hline SSV/SST & $\mathrm{mg} \cdot \mathrm{L}^{-1}$ & 0,48 & 0,46 & 0,50 \\
\hline Sólidos totais voláteis & $\mathrm{mg} \cdot \mathrm{L}^{-1}$ & $6.609,5$ & 5.261 & 7.958 \\
\hline SSVISSF & $\mathrm{mg} \cdot \mathrm{L}^{-1}$ & 0,98 & 0,86 & 1,1 \\
\hline SSV & $\mathrm{mg} \cdot \mathrm{L}^{-1}$ & 518 & 474 & 562 \\
\hline $\mathrm{DQO}_{\text {Total }}$ & $\mathrm{mg} \cdot \mathrm{L}^{-1}$ & 20.180 & 18.513 & 21.847 \\
\hline $\mathrm{DQO}_{\text {Filtrada }}$ & $\mathrm{mg} \cdot \mathrm{L}^{-1}$ & 11.783 & 10.392 & 13.174 \\
\hline $\mathrm{DBO}_{5}$ & $\mathrm{mg} \cdot \mathrm{L}^{-1}$ & 7.295 & 6.583 & 8.006 \\
\hline NTK & $\mathrm{mg} \cdot \mathrm{L}^{-1}$ & 2.423 & 2.091 & 2.951 \\
\hline Nitrogênio amoniacal & $\mathrm{mg} \mathrm{N} \cdot \mathrm{L}^{-1}$ & 2.370 & 1.894 & 2.648 \\
\hline Fósforo total & $\mathrm{mg} \mathrm{P.L^{-1 }}$ & 11 & 9,3 & 12,7 \\
\hline Ortofosfato & $\mathrm{mg} \mathrm{P.L^{-1 }}$ & 6 & 5,9 & 6,8 \\
\hline
\end{tabular}

Nota: SSV = Sólidos Suspensos Voláteis. SST = Sólidos Suspensos Totais. SSF = Sólidos Suspensos Fixos.

Ao analisar os dados da Tabela 2, observa-se que o lixiviado mostrou elevada concentração de matéria orgânica em função da $\mathrm{DQO}_{\text {Total, }}$ apresentando valor médio de $20.180 \mathrm{mg} . \mathrm{L}^{-1}$. Tendo em vista que a parcela de $\mathrm{DBO}_{5}$ corresponde a pouco mais de $36 \%$ da $\mathrm{DQO}_{\text {Total }}$ isso caracteriza condições de baixa biodegradabilidade do lixiviado e, consequentemente, desfavorece a aplicação de tratamento biológico.

Esses argumentos justificam o baixo desempenho dos processos biológicos adotados atualmente para tratar o lixiviado dos aterros sanitários em operação no Brasil, principalmente os sistemas de lagoas de estabilização.

A relação SSV/SSF representa a razão entre a fração orgânica e a fração inorgânica, indicando uma baixa relação a predominância de substância inorgânica.

\section{EFEITO DO PH NO PROCESSO DE DESSORÇÃO DE AMÔNIA DO LIXIVIADO DE ATERRO SANITÁRIO} O principal problema do lixiviado é a elevada concentração de nitrogênio amoniacal, a qual afeta a fauna e a flora dos corpos receptores aquáticos, além de inibir o metabolismo de microrganismos em processos biológicos. Analisando o comportamento do nitrogênio amoniacal para os tratamentos realizados com brita $n^{\circ} 25$ como material de recheio para as torres, apresentado na Figura 3a, o pH que resultou na maior média de remoção de nitrogênio amoniacal foi o $\mathrm{pH} 11$, sendo o valor médio inicial de $1.198 \mathrm{mg}^{\mathrm{L} \mathrm{L}^{-1}}$; após 2 horas e 40 minutos de aeração, a concentração média de nitrogênio amoniacal foi reduzida para $76 \mathrm{mg}$. $\mathrm{L}^{-1}$, apresentando eficiência de 93,6\%. Já os ensaios realizados com lixiviados tendo $\mathrm{pH}$ corrigido para 9 e 10 apresentaram, respectivamente, eficiência de $92,3 \%$ e $92,5 \%$.

De acordo com a Figura 3b, houve decréscimo da concentração inicial de nitrogênio amoniacal nos ensaios realizados com brita $\mathrm{n}^{\circ} 19$. O pH 11 também resultou em maior média de remoção de nitrogênio amoniacal, apresentando 93,2 \% durante 2 horas e 20 minutos de aeração, seguido do $\mathrm{pH}$ 10 , com $93,1 \%$, e pH 9 com $93 \%$.

A partir da Figura 3c, verifica-se que, do mesmo modo que para os ensaios realizados com brita $n^{\circ}$ 25 e $\mathrm{n}^{\circ} 19$, o $\mathrm{pH} 11$ proporcionou maior média de 

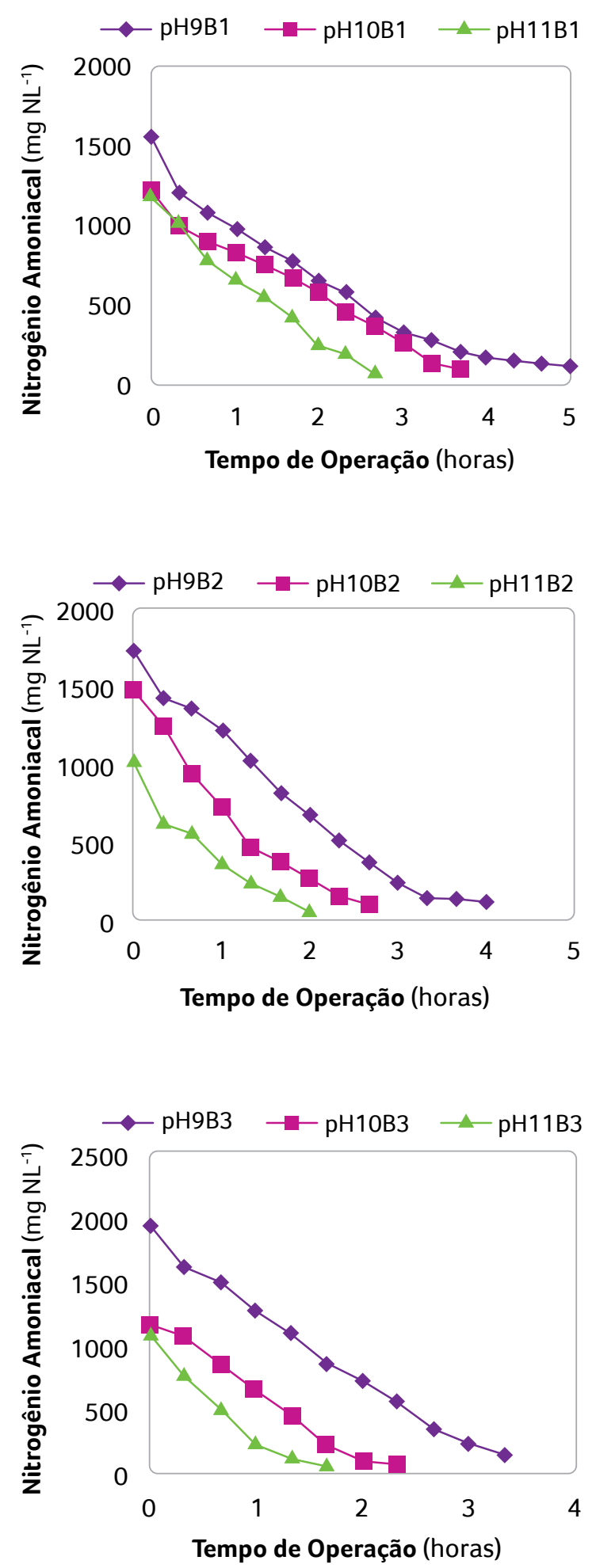

Figura 3 - Influência do pH do lixiviado de aterro sanitário no processo de dessorção de amônia quanto ao comportamento da variação temporal da concentração de nitrogênio amoniacal nos ensaios realizados com granulometria da brita do recheio das torres de: (a) $n^{\circ} 25$; (b) $n^{\circ} 19 ;(c) n^{\circ} 12$. remoção nas concentrações de nitrogênio amoniacal para os ensaios realizados com brita $n^{\circ} 12$ como material de recheio para as torres, apresentando valor médio inicial de 1.075,3 mg.L-1; após 1 hora e 40 minutos de aeração, a concentração média foi reduzida para $68,2 \mathrm{mg} \cdot \mathrm{L}^{-1}$, apresentando eficiência de $93,7 \%$. Já os ensaios realizados com lixiviado tendo $\mathrm{pH}$ corrigido para 9 e 10 apresentaram eficiência de 93,5\% e 93,6\%, respectivamente.

Apesar da diminuição da concentração de nitrogênio amoniacal, esta ainda não satisfaz a condição de lançamento do lixiviado em um corpo receptor, determinada pela Resolução CONAMA n ${ }^{\circ}$ 430/2011, sendo necessário um pós-tratamento. Com relação ao comportamento do $\mathrm{pH}$ ao longo dos ensaios, apresentado na Figura 4, constata-se que, à medida que a concentração de nitrogênio amoniacal foi reduzida, se verificou elevação nos valores do $\mathrm{pH}$ em todos os ensaios, contrariando o equilíbrio químico entre $\mathrm{NH}_{3}$ e $\mathrm{NH}_{4}^{+}$, mostrado na Equação 1. Ao contrário do ocorrido, o esperado seria o decréscimo nos valores de $\mathrm{pH}$, porém vários autores observam a mesma situação em experimentos com remoção de amônia do lixiviado por dessorção (FERREIRA et al., 2009; LEITE et al., 2009; SOUTO et al., 2009).

Esse fato pode ser explicado pelo processo de dessorção, uma vez que ele também arrasta determinadas espécies químicas presentes na composição do lixiviado, fazendo com que haja aumento nos valores de $\mathrm{pH}$. O equilíbrio químico do sistema carbonato (Equações 5 a 8) é outra possível explicação associada ao aumento do $\mathrm{pH}$. É provável que as concentrações de íons $\mathrm{H}^{+}$aumentem devido remoção de amônia do sistema, porém esses íons poderiam ser neutralizados pelo carbonato (Equação 8) promovendo a formação de dióxido de carbono $\left(\mathrm{CO}_{2}\right)$. Ainda na Equação 8 é mostrado que a retirada de gás carbônico do lixiviado durante a dessorção implicaria o consumo de íons $\mathrm{H}^{+}$ e, portanto, ocasionaria o aumento de $\mathrm{pH}$, mesmo havendo remoção de amônia. 

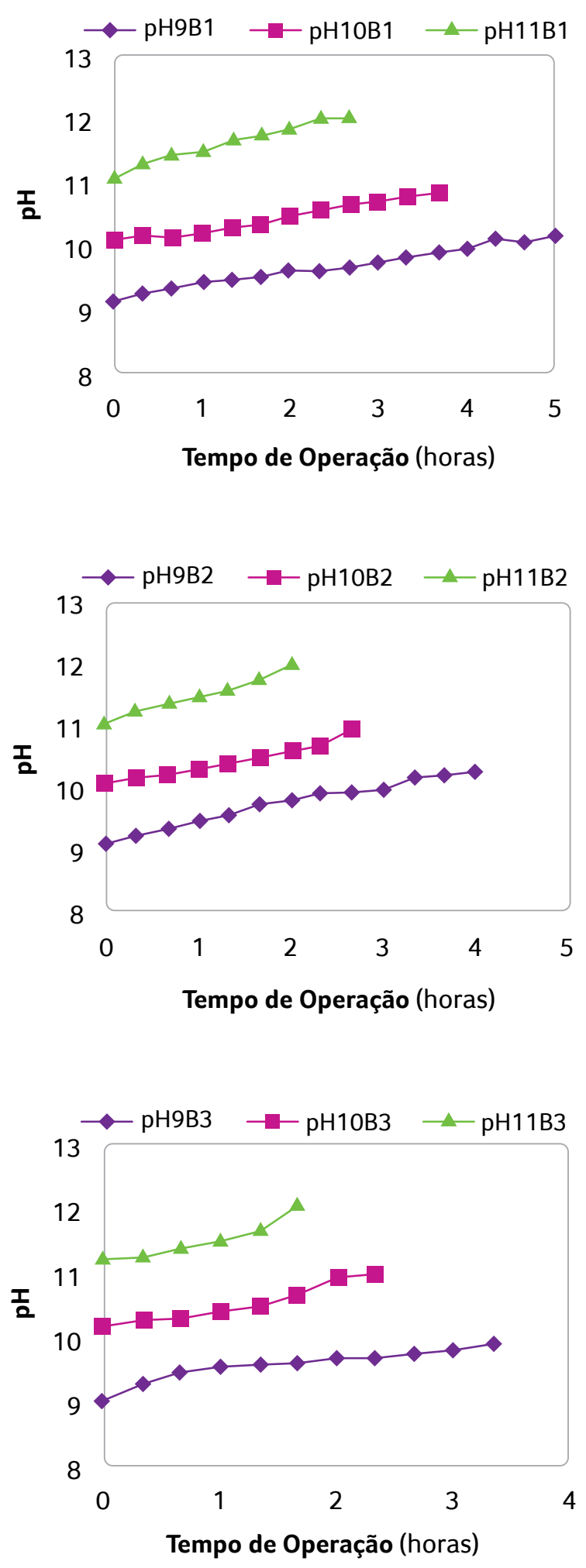

Figura 4 -Influência do $\mathrm{pH}$ do lixiviado de aterro sanitário no processo de dessorção de amônia quanto ao comportamento da variação temporal de $\mathrm{pH}$ nos ensaios realizados com granulometria da brita do recheio das torres de: (a) no 25; (b) no 19; (c) no 12.

$$
\begin{aligned}
& \mathrm{CO}_{2(\text { aq) }}+\mathrm{H}_{2} \mathrm{O} \leftrightarrow \mathrm{H}_{2} \mathrm{CO}_{3} \\
& \mathrm{H}_{2} \mathrm{CO}_{3} \leftrightarrow \mathrm{H}^{+}+\mathrm{HCO}_{3}^{-} \\
& \mathrm{HCO}_{3}^{-} \leftrightarrow \mathrm{H}^{+}+\mathrm{CO}_{3}^{-2} \\
& \mathrm{CO}_{2(\text { aq) }}+\mathrm{H}_{2} \mathrm{O} \leftrightarrow 2 \mathrm{H}^{+}+\mathrm{CO}_{3}^{-2}
\end{aligned}
$$

Quanto à concentração de alcalinidade total, pode-se observar que há decaimento na concentração em todos os tratamentos analisados. De acordo com a Figura $4 a$ as concentrações médias iniciais nos tratamentos pH9B1, pH10B1 e pH11B1 foram: 23.193,93 mg. $\mathrm{L}^{-1}, 23.535,47$ $\mathrm{mg} \cdot \mathrm{L}^{-1}$ e $25.210,97 \mathrm{mg} \cdot \mathrm{L}^{-1}$, sendo reduzidas para

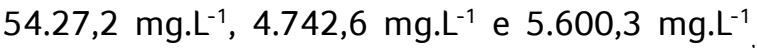
respectivamente. $\mathrm{Na}$ Figura $4 \mathrm{~b}$, verifica-se que as concentrações médias iniciais nos tratamentos pH9B2, pH10B2 e pH11B2 foram: 14.213,2 mg.L $\mathrm{L}^{-1}, 17.583,87 \mathrm{mg} \cdot \mathrm{L}^{-1}$ e $17.593,53 \mathrm{mg} \cdot \mathrm{L}^{-1}$ sendo reduzidas para 5.722,9 mg. $\mathrm{L}^{-1}, 5.448,2 \mathrm{mg} \cdot \mathrm{L}^{-1}$ e $5.510,4 \mathrm{mg} \cdot \mathrm{L}^{-1}$ respectivamente. A volatilização da amônia durante o processo de dessorção é a justificativa para a redução considerável das concentrações médias de alcalinidade total, conforme apresentado na Figura 5.

Analisando a Figura 6, constata-se o decréscimo nas concentrações dos ácidos graxos voláteis em todos os tratamentos estudados. As concentrações iniciais variaram de 3.854,3 a 2.813,6 $\mathrm{mgN} \cdot \mathrm{L}^{-1}$ e, após o período de monitoração, as concentrações residuais variaram de 818,7 a 582 $\mathrm{mgN}$. L-1 . Essa diminuição das concentrações médias dos ácidos graxos voláteis deve-se ao arraste dos ácidos orgânicos, além do arraste de outras espécies químicas de características ácidas presentes no lixiviado, durante o processo de dessorção de amônia.

Assim, conclui-se que o pH exerce influência direta no processo de dessorção de amônia. Também foi verificado que o aumento do $\mathrm{pH}$ afetou de forma positiva a eficiência da dessorção de amônia, tanto no que diz respeito à eficiência de remoção de nitrogênio amoniacal quanto ao tempo de 

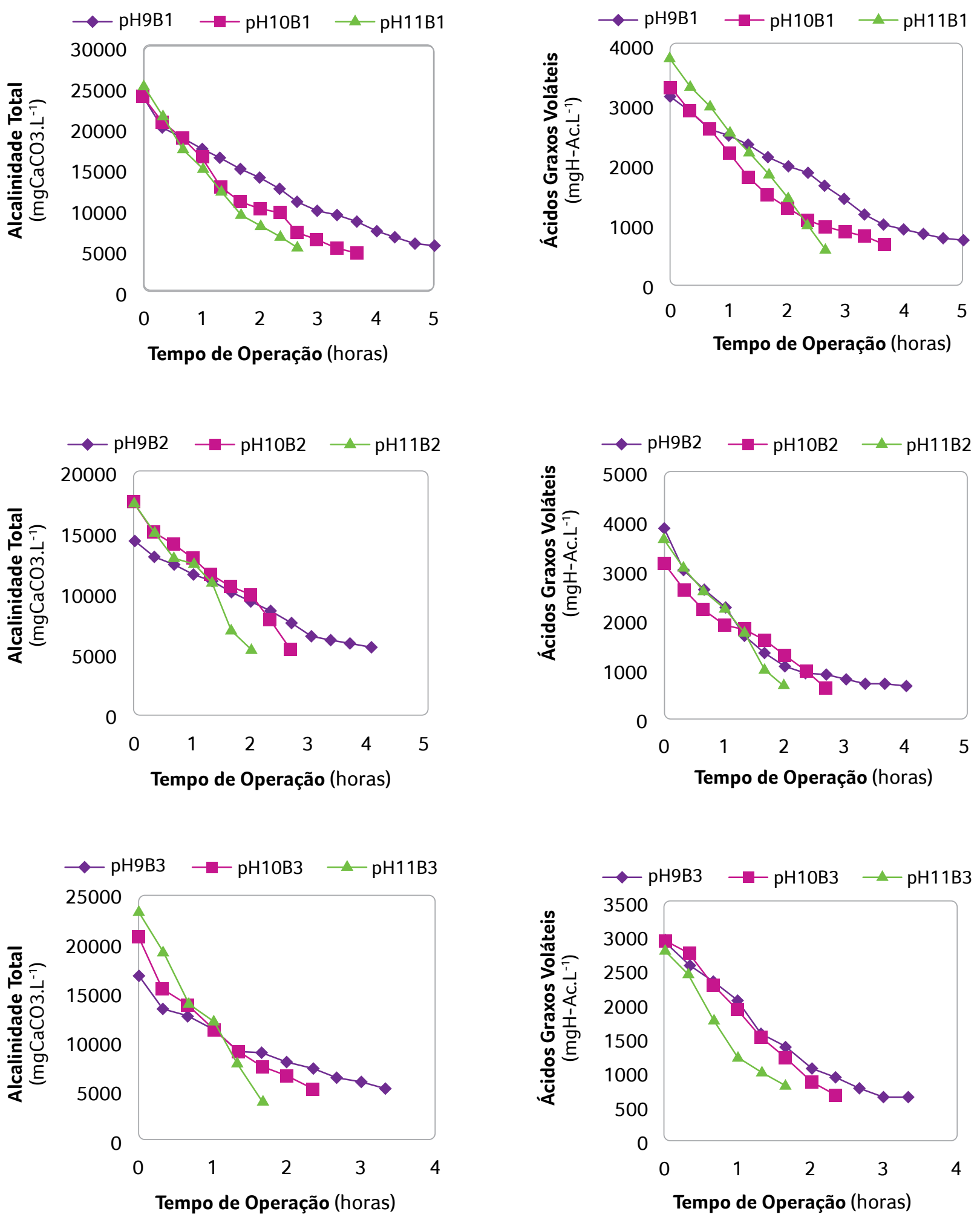

Figura 5 -Influência do $\mathrm{pH}$ do lixiviado de aterro sanitário no processo de dessorção de amônia quanto ao comportamento da variação temporal de alcalinidade total nos ensaios realizados com granulometria da brita do recheio das torres de: (a) no 25; (b) no 19; (c) no 12 .

Figura 6 - Influência do $\mathrm{pH}$ do lixiviado de aterro sanitário no processo de dessorção de amônia quanto ao comportamento da variação temporal de ácidos graxos voláteis nos ensaios realizados com granulometria da brita do recheio das torres de: (a) $n^{\circ} 25$; (b) $n^{\circ} 19$; (c) $n^{\circ} 12$. 
operação dos ensaios. A explicação para tal evento está no fato de que, quanto maior for o $\mathrm{pH}$ do lixiviado, maior será a conversão de $\mathrm{NH}_{4}{ }^{+} \mathrm{em} \mathrm{NH}_{3}$. O mesmo comportamento foi observado por Leite et al. (2009) ao estudar o efeito do pH no processo de dessorção de amônia de lixiviado de aterro sanitário em torres de recheio. Com o aumento do $\mathrm{pH}$ do lixiviado, o período de operação foi reduzido de 4 horas para 2 horas e 30 minutos.

\section{EFEITO DA GRANULOMETRIA DO MATERIAL DE RECHEIO DAS TORRES NO PROCESSO DE DESSORÇÃO DE AMÔNIA DE LIXIVIADO DE ATERRO SANITÁRIO}

Na Figura 7, é apresentado o comportamento da variação temporal de nitrogênio amoniacal para os ensaios realizados com correções de $\mathrm{pH}$ do lixiviado para 9,10 e 11, com utilização de brita $n^{\circ} 25,19$ e 12 como material de recheio para o processo de dessorção de amônia do lixiviado de aterro sanitário.

Observa-se que, nos ensaios realizados com brita de granulometria $n^{\circ} 25$, os tempos de operação para os tratamentos de $\mathrm{pH}$ 9, 10 e 11 foram: 5 horas, 3 horas e 40 minutos e 2 horas e 40 minutos, sendo reduzidos para 3 horas e 20 minutos, 2 horas e 20 minutos e 1 hora e 40 minutos, respectivamente, nos ensaios realizados com brita de granulometria $n^{\circ} 12$. A redução no tempo de operação dos ensaios deve-se à forte influência da granulometria do recheio das torres no processo de dessorção de amônia de lixiviado de aterro sanitário.

O principal fator responsável por esse acontecimento é a transferência de massa, uma vez que, quanto menor a granulometria do material de recheio, maior a velocidade de transferência de massa e, consequentemente, menor o tempo de realização do ensaio, tornando maior a eficiência do processo.
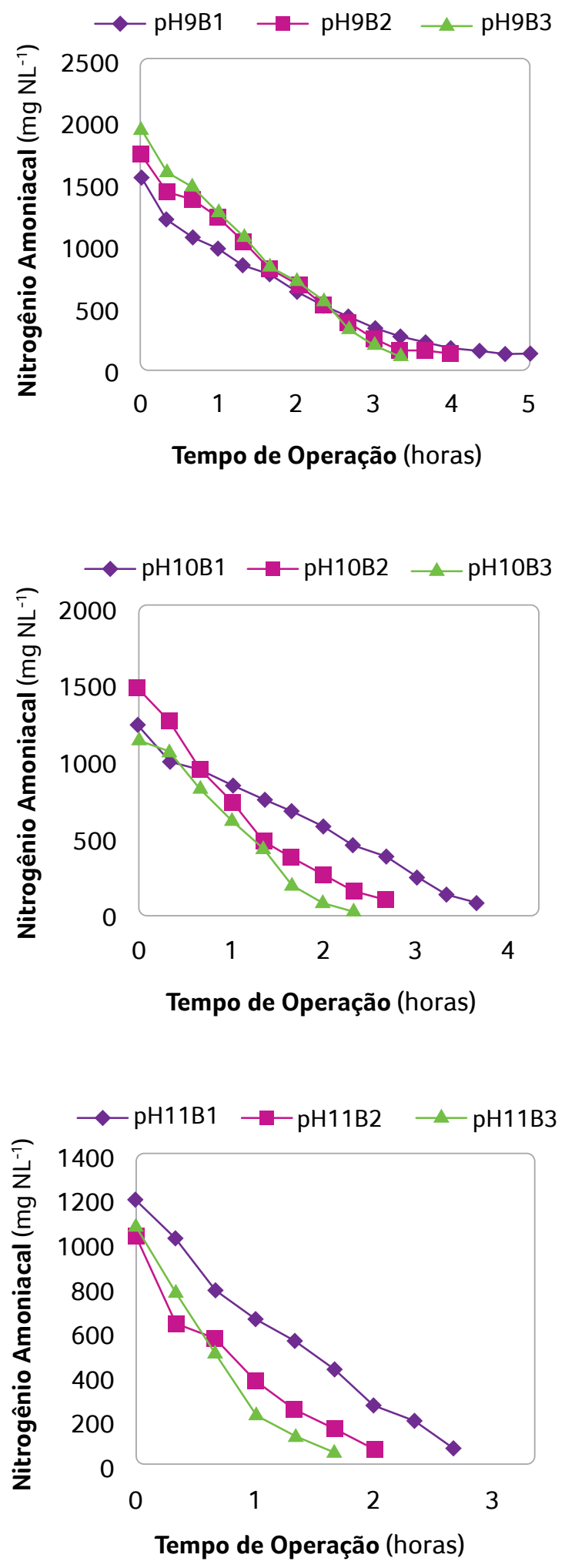

Figura 7 - Influência da granulometria do material de recheio das torres quanto ao comportamento da variação temporal da concentração de nitrogênio amoniacal sob os ensaios realizados com correção de pH para: (a) pH 9; (b) $\mathrm{pH} 10$; (c) $\mathrm{pH} 11$. 
Tabela 3 - Dados relativos aos custos associados ao processo de dessorção de amônia realizado em torres de recheio.

\begin{tabular}{|c|c|c|c|c|c|c|c|c|c|}
\hline Parâmetro & Р9B1 & P10B1 & P11B1 & Р9B2 & P10B2 & P11B2 & Р9В3 & Р10B3 & P11B3 \\
\hline $\begin{array}{l}\text { Energia elétrica } \\
\text { ( } \$ \$ \mathrm{~m}^{3} \text { Lixiviado) }\end{array}$ & 57,20 & 41,86 & 30,50 & 45,76 & 30,43 & 22,88 & 38,09 & 26,65 & 18,99 \\
\hline Concentração de cal $\left(\mathrm{kg} / \mathrm{m}^{3}\right)$ & 6,5 & 19,7 & 35 & 6,7 & 19,9 & 35,9 & 6,4 & 19,5 & 35,40 \\
\hline Concentração de $\mathrm{HCl}(\mathrm{mL} / \mathrm{L})$ & 2,9 & 7,0 & 11,4 & 2,9 & 7,4 & 10,7 & 3,2 & 7,3 & 10,70 \\
\hline $\mathrm{R} \$ \mathrm{cal} / \mathrm{m}^{3}$ lixiviado & 3,25 & 9,85 & 17,50 & 3,35 & 9,95 & 17,95 & 3,20 & 9,75 & 17,70 \\
\hline $\mathrm{R} \$ \mathrm{cal} / \mathrm{m}^{3}$ lixiviado & 2,20 & 126,00 & 205,20 & 52,20 & 133,20 & 192,60 & 57,60 & 131,40 & 192,60 \\
\hline Total ( $\mathrm{R} \$ / \mathrm{m}^{3}$ lixiviado) & 112,65 & 177,71 & 253,20 & 101,31 & 173,58 & 233,43 & 98,89 & 167,80 & 229,20 \\
\hline
\end{tabular}

\section{ESTIMATIVA DE CUSTO PARA O PROCESSO DE DESSORÇÃO DE AMÔNIA EM LIXIVIADOS DE ATERRO SANITÁRIO}

Para a estimativa de custo do processo de dessorção de amônia em lixiviado de aterro sanitário realizado em torres de recheio, levaram-se em consideração as despesas com o consumo das espécies químicas, hidróxido de cálcio, ácido clorídrico e energia elétrica na utilização do compressor de ar. Na Tabela 3 são apresentados os dados relativos a esses custos.

Analisando os dados, verifica-se que os custos operacionais são bastante elevados, em especial no caso dos experimentos P11B1, P11B2 e P11B3. Isso se deve ao uso de altas quantidades de ácido clorídrico, substância ácida utilizada para baixar o pH do efluente para 8, com o intuito de conduzi-lo a um tratamento posterior, para adequar o efluente às condições de lançamento exigidas pela resolução do CONAMA.

A quantidade de ácido clorídrico utilizado no fim de cada experimento foi o fator determinante para o alto custo operacional do processo. Observa-se que, independentemente da granulometria do recheio utilizado nas torres de dessorção de amônia durante os ensaios, houve elevação nos custos do processo de acordo com o aumento do $\mathrm{pH}$. Por esse motivo, os experimentos P9B1, P9B2 e P9B3 oferecem melhores condições econômicas, mas não representam uma boa alternativa devido ao elevado tempo de operação.
Os experimentos P9B3, P10B3 e P11B3 apresentaram menores custos associados ao processo de dessorção de amônia quando comparados aos demais experimentos realizados sob as mesmas condições de $\mathrm{pH}$ e diferentes condições de granulometria. Isso ocorre devido ao decréscimo do tempo de operação dos ensaios que foram realizados com brita $\mathrm{n}^{\circ} 12$ como material de recheio para as torres de dessorção, uma vez que, quanto menor o tempo de operação, menor o consumo de energia elétrica.

\section{CONCLUSÕES}

(1) O lixiviado de aterro sanitário da cidade de João Pessoa (PB) apresenta-se com baixo potencial de degradação biológica.

(2) O processo de dessorção de amônia em torres de recheio constitui alternativa eficiente para o tratamento de lixiviado de aterro sanitário, favorecendo a remoção de elevada concentração de nitrogênio amoniacal durante baixo tempo de operação, obtendo remoção de nitrogênio amoniacal superior a $92 \%$ para todos os tratamentos realizados.

(3) Os ensaios realizados com recheio de menor granulometria nas torres e maior correção de $\mathrm{pH}$ para o lixiviado apresentaram maior remoção da concentração de nitrogênio amoniacal e menor tempo de operação, confirmando que a granulometria e o $\mathrm{pH}$ exercem influência no processo de dessorção de amônia. 
(4) O consumo de energia, obrigatoriamente, depende da duração do ensaio e concentração final de nitrogênio amoniacal que se deseja obter.

(5) O tempo de operação dos tratamentos variou de 1 hora e 40 minutos a 5 horas. Portanto, como os custos inerentes ao processo de aeração são diretamente proporcionais ao tempo de operação, quanto mais elevado o $\mathrm{pH}$, menor os custos com aeração, porém maior os custos com as espécies alcalinizantes.

(6) Estima-se que o custo operacional do processo de dessorção de amônia em torres de recheio no lixiviado de aterro sanitário da cidade de João Pessoa (PB) sob as mesmas condições do tratamento $\mathrm{P} 11 \mathrm{~B} 3$, que apresentou maior eficiência, é de $\mathrm{R} \$$ 229,20 por $1 \mathrm{~m}^{3}$ de lixiviado.

(7) $\mathrm{O}$ efluente produzido pelas torres de recheio apresentou baixa concentração de nitrogênio amoniacal. Essas características favorecem um posterior tratamento biológico do lixiviado, visando ao cumprimento das condições padrões exigidas pelo CONAMA.

\section{REFERÊNCIAS}

ABBAS, A. A.; GUO, J. S.; PING, L. Z.; YA, P. Y.; AL-REKABI, W. S.; Review on Landfill Leachate Treatments. American Journal of Applied Sciences, v. 6, n. 4, p.672-684, 2009.

ABRELPE - Associação Brasileira de Empresas de Limpeza Pública e Resíduos Especiais. Panorama de Resíduos Sólidos no Brasil 2012. São Paulo: ABRELPE, 2012.

APHA - American Public Health Association. Standard Methods for the Examination of Water and Wastewater. 21th ed. Washington, DC: American Public Health Association, 2005.

ASSOCIAÇÃO BRASILEIRA DE NORMAS TÉCNICAS - ABNT. Agregados para concreto - Especificação - NBR - 7211. Rio de Janeiro, 2005.

ATMACA, E. Treatment of landfill leachate by using electro-Fenton method. Journal of Hazardous Materials, v. 163, n. 1, p. 109114, 2009.

BRASIL. Conselho Nacional de Meio Ambiente. Dispõe sobre condições e padrões de lançamento de efluentes, complementa e altera a Resolução no 357, de 17 de março de 2005, do Conselho Nacional do Meio Ambiente - CONAMA. Resolução 430, de 13 de maio de 2011.
CAMPOS, D. C.; LEITE V. D.; LOPES, W. S.; RAMOS, P. C. A. Stripping de Amônia de Lixiviado de Aterro Sanitário em Reatores de Fluxo Pistonado. Tecno-lógica, Santa Cruz do Sul, v. 14, p. 52-60, 2010.

DI IACONI, C.; PAGANO, M.; RAMADORI, R.; LOPEZ, A. Nitrogen recovery from a stabilized municipal landfill leachate. Bioresource Technology, v. 101, n. 6, p. 1732-1736, 2010.

FERREIRA, J. A.; MANNARINO, C. F.; MOREIRA, J. C.; ARIAS, A. R. L.; BILLA, D. M. Avaliação do tratamento combinado de lixiviado de aterros de resíduos solídos urbanos e esgoto doméstico pelo processo de lodos ativados. In: CONGRESSO BRASILEIRO DE ENGENHARIA SANITÁRIA E AMBIENTAL, 25, 2009, Recife. Anais... Recife: ABES, 2009.

FOUST, A. S.; WENZEL, L. A.; CLUMP, C. W.; MAUS, L.; ANDERSEN, L. B. Princípios das Operações Unitárias. Rio de Janeiro: Guanabara Dois, p. 338, 1982.

GOMIDE, R. Operações Unitárias. Operações de transferência de massa. São Paulo, v.4, p. 435, 1987.

KIM, D.; RYU, H. D.; KIM, M. S.; KIM, J.; LEE, S. I. Enhancing struvite precipitation potential for ammonia nitrogen removal in $\mathbf{m u}$ nicipal landfill leachate. Journal of Hazardous Materials, v. 146, n. 1-2, p. 81-85, 2007.

KURNIAWAN, T. A.; LO, W. H.; CHAN, G. Y. Physico-chemical treatments for removal of recalcitrant contaminants from landfill leachate. Journal of Hazardous Materials, v. 129, n. 1-3, p. 80$100,2006$.

LEITE, V. D.; FERNANDES, F.; JUCÁ, J. F. T.; GOMES, L. P.; LOPES, W. S.; SOUSA, J. T.; SILVA, F. M. S.; CAETANO, M. O. Estudo do Processo de Stripping de Amônia de Lixiviado de Aterro Sanitário. In: Estudo de caracterização e tratabilidade de lixiviado de aterro sanitário para condições brasileira. Rio de Janeiro: ABES, p. 60 - 96, 2009.

METCALF \& EDDY. Waste engineering: Treatment and reuse. 4th ed. Boston: McGraw-Hill, 2003.

RENOU, S.; GIVAUDAN, J. G.; POULAIN, S.; DIRASSOUYAN, F.; MOULIN,P. Landfill leachate treatment: Review and opportunity. Journal of Hazardous Materials, v. 150, n. 3, p. 468-493, 2008.

SAWYER, N.A.; CHAMBERS, S.M.; CAIRNEY, J.W.G. Utilisation of inorganic and organic phosphorus sources by isolates of Amanita muscaria and Amanita species native to temperate eastern Australia. Australian Journal of Botany, v.51, p.151-158, 2003.

SINGH, S. K.; TOWNSEND, T. G.; MAZYCK, D.; BOYER, T. H. Equilibrium and intra-particle diffusion of stabilized landfill leachate onto micro- and meso-porous activated carbon. Water Research n. 46, p. 491-499, 2012.

SOUTO, G. D. B. Lixiviado de aterros sanitários brasileiros - estudo de remoção do nitrogênio amoniacal por processo de arraste com ar ("stripping"). Tese de Doutorado - Escola de Engenharia de São Carlos. Universidade de São Paulo. São Carlos -SP. 2009. 